\title{
Caudal regression syndrome and a pelvic kidney: case report
}

\author{
Dany Hage ${ }^{1}$, Joe Iwanaga ${ }^{1}$, Aaron S. Dumont ${ }^{1}$, R. Shane Tubbs ${ }^{1,2,3,4}$ \\ ${ }^{1}$ Department of Neurosurgery, Tulane Center for Clinical Neurosciences, Tulane University School of Medicine, New Orleans, LA, ${ }^{2}$ Department of \\ Structural and Cellular Biology, Tulane University School of Medicine, New Orleans, LA, ${ }^{3}$ Department of Neurosurgery and Ochsner Neuroscience \\ Institute, Ochsner Health System, New Orleans, LA, USA, ${ }^{4}$ Department of Anatomical Sciences, St. George's University, St. George's, Grenada, West \\ Indies
}

\begin{abstract}
Caudal regression syndrome (CRS) is a rare congenital variation. A high incidence of renal and genitourinary malformations has been observed in patients with CRS, with the most common being neurogenic bladder and renal agenesis. We report a rare case report documenting both CRS and a pelvic kidney found during a diagnostic magnetic resonance imaging. Although renal anatomy variants are found in patients with CRS, a pelvic kidney is normally not part of the constellation of findings in this malformation. As seen in our patient, a pelvic kidney should be considered in patients suspected of having CRS.
\end{abstract}

Key words: Caudal regression syndrome, Pelvic kidney, Magnetic resonance imaging, Renal malformation, Spinal agenesis

Received March 15, 2020; Revised April 25, 2020; Accepted May 8, 2020

\section{Introduction}

Caudal regression syndrome (CRS) is a rare congenital abnormality that commonly presents with varying degrees of caudal vertebral agenesis or dysgenesis, in addition to malformations of the spinal cord [1]. There is a wide variety of associated variations in patients with CRS relating to the anatomical level of their spinal agenesis [1]. When compared with other neural tube defects, CRS patients have a much higher incidence of renal and genitourinary malformations and have a high risk of developing renal function impairment [2]. The severity of the disorder has been observed as being inversely proportional to the level of residual spinal cord function [3]. The incidence of CRS is uncommon with an estimated rate of $0.1-0.25$ per 10,000 uncomplicated preg-

\section{Corresponding author:}

Joe Iwanaga (iD

Department of Neurosurgery, Tulane Center for Clinical Neurosciences, Tulane University School of Medicine, New Orleans, LA 70112, USA

E-mail: iwanagajoeca@gmail.com nancies [4]. In this report, we present a rare case of CRS in a patient with partial sacral agenesis and a pelvic kidney and discuss the importance of screening and early intervention.

\section{Case Report}

A 13-month-old female presented with chronic urinary bladder infections. The child was the product of a normal gestation and the mother was not diabetic. No cutaneous stigmata were identified on the back of the patient. The patient was walking with assistance by the parents. The lower limbs were well formed although the mass of the calf was felt to be slightly smaller than normal for age. Ultrasound images were suggestive of urinary retention. On plain abdominal X-ray, hypoplasia of the lower sacrum was observed. The S3-5 segments of the sacrum were absent (Fig. 1). A T1weighted sagittal magnetic resonance imaging demonstrated that the spinal cord terminated at the level of the mid L1 vertebral body and the distal cord had a typical "drumstick" appearance (Fig. 2). No other intradural malformations were noted on imaging e.g., fatty infiltrated filum terminale or other forms of tethered spinal cord. The left kidney was lo-

\section{Copyright $@ 2020$. Anatomy \& Cell Biology}

This is an Open Access article distributed under the terms of the Creative Commons Attribution Non-Commercial License (http://creativecommons.org/licenses/by-nc/4.0/) which permits unrestricted non-commercial use, distribution, and reproduction in any medium, provided the original work is properly cited. 


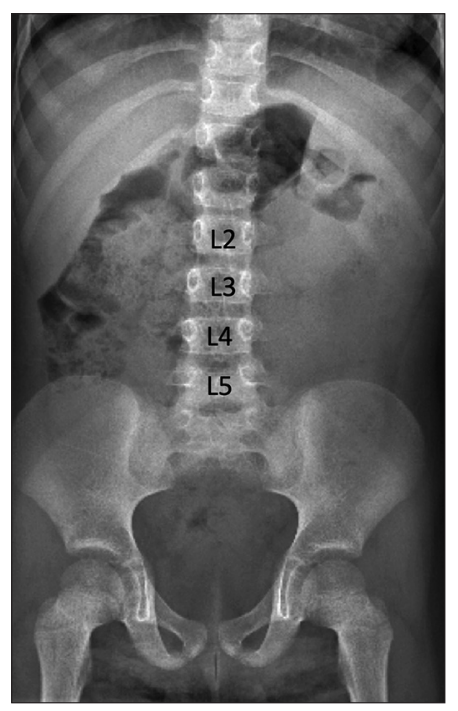

Fig. 1. Plain abdominal X-ray showing hypoplasia of the distal sacrum.

cated between the L2 to L4 vertebral bodies, and the pelvis was occupied by a large pelvic kidney (Fig. 2).

\section{Discussion}

While the exact mechanism and etiology remain unknown, there is a significantly higher incidence associated with maternal diabetes, where 1 in every 350 births is affected [4].

Additionally, experimental studies in mice have demonstrated teratogenic effects of retinoic acid, wherein exposure of retinoic acid receptor agonists to pregnant mice induced CRS and renal anomalies in their offspring [5].

Studies conducted by Torre et al. [6] have made efforts toward quantifying the incidence of renal anomalies in patients with neural tube defects. In these studies, the most common anomalies affecting the CRS population were neurogenic bladder (60\%), renal agenesis $(13 \%-20 \%)$, and impaired renal function $(8 \%-12 \%)[2,6]$. In the present case, however, the right kidney failed to ascend during the ninth week of embryogenesis and remained in the pelvis.

Pelvic kidneys are typically incidental findings as they tend to be asymptomatic [7]. There is an estimated incidence of 1 in 2,200-3,000 [8]. Even though they are not ordinarily pathogenic, they may be indicative of other conditions including nephrolithiasis, hydronephrosis, uteropelvic junction obstruction, and the development of calices [7, 8]. It has been noted that $22 \%-37 \%$ of patients with pelvic kidneys have also been diagnosed with uteropelvic junction obstruction

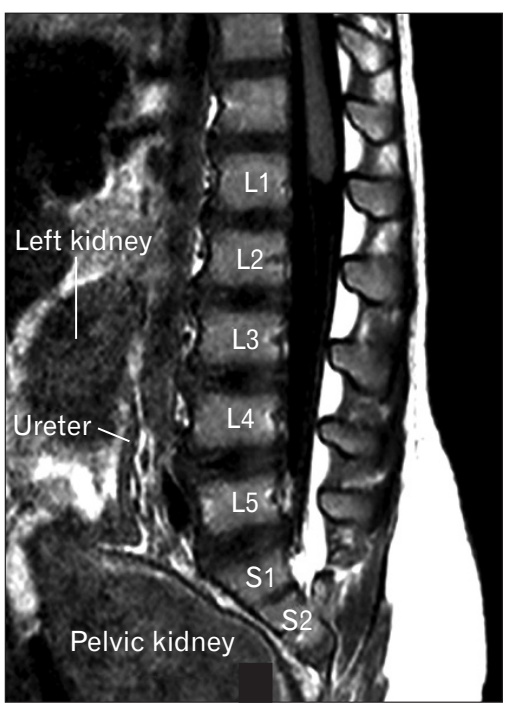

Fig. 2. T1-weighted sagittal magnetic resonance imaging. Note the lower left kidney located in the midline with the ureter posteriorly and a large pelvic kidney.

[8]. Early diagnosis of uteropelvic junction obstruction is imperative as it is classified as the most common prenatally detected disease that can lead to hydronephrosis [9].

Obstructive diseases can increase the chances of infant death, kidney failure, and chronic kidney disease $[9,10]$. The current hypothesis is that patients with uteropelvic junction obstruction have ureters that insert into the renal pelvis at a higher than normal location, which delays renal emptying $[7,11]$. Furthermore, there is a statistically significant correlation between insufficient bladder voiding and renal damage in the CRS patient population [12]. Since the incidence of neurogenic bladder in the CRS population is $60 \%$ $[2,6]$, it is imperative that all CRS patients, especially those presenting with a pelvic kidney as with the present case, be thoroughly evaluated for urinary obstruction. CRS patients are often asymptomatic until their condition has progressed, therefore, utilizing a standardized system for scoring dysfunctional voiding symptoms may be the best method for assessing these patients [13]. This testing may also aid with understanding the underlying neurological issue with the spinal cord [12]. Although CRS patients have neuromuscular challenges, they have the capacity to live fairly normal lives. Thus, early urologic testing and intervention are necessary to lower their risk of developing chronic conditions that will impact their quality of life [12].

In conclusion, although renal anatomy variants are found in patients with CRS, a pelvic kidney is normally not part of 
the constellation of findings in this malformation. As seen in our patient, a pelvic kidney should be considered in patients suspected of having CRS.

\section{ORCID}

Dany Hage: https://orcid.org/0000-0002-2404-3449

Joe Iwanaga: https://orcid.org/0000-0002-8502-7952

Aaron S. Dumont: https://orcid.org/0000-0002-8077-8992

R. Shane Tubbs: https://orcid.org/0000-0003-1317-1047

\section{Author Contributions}

Conceptualization: JI, RST. Data acquisition: JI, RST. Data analysis or interpretation: DH, JI. Drafting of the manuscript: DH, JI. Critical revision of the manuscript: ASD, RST. Approval of the final version of the manuscript: all authors.

\section{Conflicts of Interest}

No potential conflict of interest relevant to this article was reported.

\section{References}

1. Nievelstein RA, Valk J, Smit LM, Vermeij-Keers C. MR of the caudal regression syndrome: embryologic implications. AJNR Am J Neuroradiol 1994;15:1021-9.

2. Torre M, Buffa P, Jasonni V, Cama A. Long-term urologic outcome in patients with caudal regression syndrome, compared with meningomyelocele and spinal cord lipoma. J Pediatr Surg 2008;43:530-3.
3. Tortori-Donati P, Fondelli MP, Rossi A, Raybaud CA, Cama A, Capra V. Segmental spinal dysgenesis: neuroradiologic findings with clinical and embryologic correlation. AJNR Am J Neuroradiol 1999;20:445-56.

4. Sen KK, Patel M. Caudal regression syndrome. Med J Armed Forces India 2007;63:178-9.

5. Tse HK, Leung MB, Woolf AS, Menke AL, Hastie ND, Gosling JA, Pang CP, Shum AS. Implication of Wt1 in the pathogenesis of nephrogenic failure in a mouse model of retinoic acid-induced caudal regression syndrome. Am J Pathol 2005;166:1295307.

6. Torre M, Guida E, Bisio G, Scarsi P, Piatelli G, Cama A, Buffa P. Risk factors for renal function impairment in a series of 502 patients born with spinal dysraphisms. J Pediatr Urol 2011;7:3943.

7. Eid S, Iwanaga J, Loukas M, Oskouian RJ, Tubbs RS. Pelvic kidney: a review of the literature. Cureus 2018;10:e2775.

8. Cinman NM, Okeke Z, Smith AD. Pelvic kidney: associated diseases and treatment. J Endourol 2007;21:836-42.

9. Mesrobian HG, Mirza SP. Hydronephrosis: a view from the inside. Pediatr Clin North Am 2012;59:839-51.

10. Roth KS, Koo HP, Spottswood SE, Chan JC. Obstructive uropathy: an important cause of chronic renal failure in children. Clin Pediatr (Phila) 2002;41:309-14

11. Natsis K, Piagkou M, Skotsimara A, Protogerou V, Tsitouridis I, Skandalakis P. Horseshoe kidney: a review of anatomy and pathology. Surg Radiol Anat 2014;36:517-26.

12. Moritoki Y, Kojima Y, Kamisawa H, Mizuno K, Kohri K, Hayashi Y. Neuropathic bladder caused by caudal regression syndrome without any other neurogenic symptoms. Case Rep Med 2012;2012:982418.

13. Farhat W, Bägli DJ, Capolicchio G, O'Reilly S, Merguerian PA, Khoury A, McLorie GA. The dysfunctional voiding scoring system: quantitative standardization of dysfunctional voiding symptoms in children. J Urol 2000;164(3 Pt 2):1011-5. 